\title{
Yeast product supplementation modulated feeding behavior and metabolism in transition dairy cows
}

\author{
K. Yuan, ${ }^{*}$ T. Liang,† M. B. Muckey, ${ }^{*}$ L. G. D. Mendonça, ${ }^{*}$ L. E. Hulbert, ${ }^{*}$ C. C. Elrod,‡ and B. J. Bradford ${ }^{* 1}$ \\ ${ }^{*}$ Department of Animal Sciences and Industry, Kansas State University, Manhattan 66506 \\ †GM Powertrain, Pontiac, MI 48340 \\ ¥Vi-COR Inc., Mason City, IA 50402
}

\section{ABSTRACT}

Yeast supplementation has been shown to increase feed intake and production in some studies with early lactation dairy cows, but the mechanisms underlying such an effect remain unknown. The objective of this study was to assess the effects of supplementing a yeast product derived from Saccharomyces cerevisiae on production, feeding behavior, and metabolism in cows during the transition to lactation. Forty multiparous Holstein cows were blocked by expected calving date and randomly assigned within block to 1 of 4 treatments $(\mathrm{n}=10)$ from $21 \mathrm{~d}$ before expected calving to 42 d postpartum. Rations were top-dressed with a yeast culture plus enzymatically hydrolyzed yeast (YC-EHY; Celmanax, Vi-COR Inc., Mason City, IA) at the rate of $0,30,60$, or $90 \mathrm{~g} / \mathrm{d}$ throughout the experiment. Dry matter and water intake, feeding behavior, and milk production were monitored. Plasma samples collected on $-21,-7,1,4,7,14,21$, and $35 \mathrm{~d}$ relative to calving were analyzed for glucose, $\beta$-hydroxybutyrate, and nonesterified fatty acids. Data were analyzed using mixed models with repeated measures over time. Pre- or postpartum dry matter intake and water intake did not differ among treatments. Quadratic dose effects were observed for prepartum feeding behavior, reflecting decreased meal size, meal length, and intermeal interval, and increased meal frequency for cows received 30 and $60 \mathrm{~g} / \mathrm{d}$ of YC-EHY. Postpartum feeding behavior was unaffected by treatments. Milk yields were not affected $(45.3,42.6,47.8$, and $46.7 \mathrm{~kg} / \mathrm{d}$ for $0,30,60$, and $90 \mathrm{~g} / \mathrm{d}$, respectively) by treatments. Tendencies for increased percentages of milk fat, protein, and lactose were detected for cows receiving YC-EHY. Supplementing YC-EHY increased plasma $\beta$-hydroxybutyrate and tended to decrease (quadratic dose effect) glucose but did not affect nonesterified fatty acids. Yeast product supplementation during the transition period did

Received June 9, 2014.

Accepted October 9, 2014.

${ }^{1}$ Corresponding author: bbradfor@ksu.edu not affect milk production and dry matter intake but modulated feeding behavior and metabolism.

Key words: feeding behavior, metabolism, transition cow, yeast

\section{INTRODUCTION}

The transition from late gestation to early lactation in dairy cows is characterized by dramatic energy requirements for milk synthesis and secretion, inadequate feed intake, and substantial metabolic stress (Grummer, 1995). Therefore, the transition period directly determines the lactational performance, health, and profitability of dairy cows. Yeast products derived from Saccharomyces cerevisiae have been added to diets in an attempt to improve ruminal fermentation, feed intake, and milk yield. Dann et al. (2000) reported that yeast culture supplementation at $60 \mathrm{~g} / \mathrm{d}$ from approximately $21 \mathrm{~d}$ prepartum to $140 \mathrm{~d}$ postpartum increased DMI during both the last $7 \mathrm{~d}$ prepartum $(P=0.01)$ and the first $42 \mathrm{~d}$ of lactation $(P=0.05)$ in Jersey cows. A recent transition cow study (Ramsing et al., 2009) reported that yeast culture supplementation at $57 \mathrm{~g} / \mathrm{d}$ from approximately $21 \mathrm{~d}$ prepartum to $21 \mathrm{~d}$ postpartum improved prepartum DMI $(P<0.01)$ and postpartum milk production $(P<0.01)$. Desnoyers et al. (2009) conducted a quantitative meta-analysis using 157 experiments to assess the responses to yeast supplementation and found that yeast products increased rumen $\mathrm{pH}$, DMI, milk yield, and tended to increase milk fat content.

These data indicate that yeast products may improve the production of dairy cows, but mechanisms explaining the link between yeast supplementation and increased productivity remain unclear. Some investigators have proposed that metabolic activity of yeast in the rumen can use oxygen that would otherwise have toxic effects on the anaerobic microbes that are responsible for most ruminal digestion (Newbold et al., 1996). However, this proposal almost certainly does not account for the reported responses to yeast culture products (Poppy et al., 2012), which contain very few live yeast cells. Alternatively, cell surface antigens or in- 
tracellular growth factors produced by yeast could alter ruminal fermentation, function of the gastrointestinal epithelium, or both (Callaway and Martin, 1997). At the whole-animal level, alteration of immune function could also be important for productivity responses to dietary yeast supplements (Zaworski et al., 2014).

The objectives of this study were to assess whether a yeast product alters milk production, feeding behavior, and biomarkers of lipid and glucose metabolism in transition dairy cows.

\section{MATERIALS AND METHODS}

The Kansas State University Institutional Animal Care and Use Committee approved all experimental procedures.

\section{Design and Treatments}

Forty multiparous Holstein transition cows from the Kansas State University Dairy Cattle Teaching and Research Facility were used in a randomized complete block design. Cows were blocked by expected calving date (10 blocks) and randomly assigned within block to 1 of 4 treatments $21 \mathrm{~d}$ before their expected calving date. Cows remained on their respective treatments through $42 \mathrm{~d}$ postpartum. Cows received a product containing yeast culture plus enzymatically hydrolyzed yeast (YC-EHY; Celmanax, Vi-COR, Mason City, IA) at a rate of $0,30,60$, or $90 \mathrm{~g} / \mathrm{d}$. These doses are consistent with the levels of supplementation reported in previous studies (Ramsing et al., 2009; Zaworski et al., 2014), and were chosen to characterize the response surface across the range of feeding rates that have been efficacious. The YC-EHY was administered daily to each cow in the treatment groups by top-dressing and manually mixing the premix into the upper part of each TMR. Diets were formulated to meet or exceed NRC (2001) requirements (Table 1). Samples of corn silage were collected weekly; all other dietary ingredients were collected every 2 wk and stored at $-20^{\circ} \mathrm{C}$. Upon study completion, feed ingredients were composited monthly for analysis by near-infrared reflectance spectroscopy by Dairy One Forage Laboratory (Ithaca, NY).

\section{Management of Cows, Data Collection, and Sample Analysis}

Cows used in the study had a dry period of 58.4 $\pm 6.5 \mathrm{~d}$ (mean $\pm \mathrm{SD}$ ) and consumed a diet containing grass hay, corn silage, wet corn gluten feed, and a grain/micronutrient supplement during the first $30 \mathrm{~d}$ of the dry period, providing an estimated 2.18 Mcal of $\mathrm{ME} / \mathrm{kg}$ of DM (NRC, 2001). Cows were moved into the maternity barn approximately 1 wk before entering the study and were allowed ad libitum access to the designated treatment rations by an electronic gating system (Roughage Intake System, Insentec B.V., Marknesse, the Netherlands). After parturition, cows were moved into a tie-stall facility, where they remained through $42 \mathrm{~d}$ postpartum. Individual feed bunks in the tiestall facility were suspended from load cells, and bunk weights were monitored continuously by computer. Feed weights and times were stored before and immediately after any deviation in bunk weight. Dry cows were fed twice daily (1100 and $1800 \mathrm{~h}$ ), and lactating cows were fed twice daily (1200 and $1900 \mathrm{~h}$ ). All cows were fed for ad libitum intake. All feeding activity, including meal length and size, were recorded electronically. Feed refusals were measured daily and as-fed feed intake of each cow was calculated. As-fed ration consumption was adjusted for DM content for determination of meal and daily DMI. Dry matter percentage was determined for each monthly composited feed ingredient; these val-

Table 1. Ingredient and nutrient composition of diets

\begin{tabular}{lcc}
\hline Item & Prepartum & Postpartum \\
\hline Ingredient, \% of DM & & \\
Corn silage & 29.5 & 15.9 \\
WCGF $^{1}$ & 21.3 & 34.3 \\
Alfalfa hay & - & 14.2 \\
Wheat straw & 10.9 & 3.3 \\
Prairie hay & 16.8 & - \\
Cottonseed & - & 5.0 \\
Ground corn & 3.4 & 11.2 \\
Dry-rolled sorghum grain & 3.4 & 6.4 \\
Mechanically extracted soybean meal ${ }^{2}$ & 12.3 & 4.8 \\
Molasses & 1.2 & 1.2 \\
Ca salts of long-chain fatty acids & & 0.8 \\
Micronutrient premix & & \\
Nutrient, \% of DM & 1.3 & 2.9 \\
DM, \% as-fed & & \\
CP & 45.4 & 51.1 \\
Starch & 13.0 & 17.7 \\
ADF & 21.1 & 20.2 \\
NDF & 24.4 & 16.9 \\
NFC & 42.5 & 31.0 \\
Ether extract & 33.8 & 41.1 \\
Ash & 3.3 & 4.2 \\
\hline
\end{tabular}

${ }^{1}$ Wet corn gluten feed, SweetBran, Cargill Inc. (Blair, NE).

${ }^{2}$ Soy Best, Grain States Soya (West Point, NE).

${ }^{3}$ Megalac-R, Church \& Dwight Co (Princeton, NJ).

${ }^{4}$ Prepartum premix consisted of $53.0 \%$ vitamin E premix (44 IU/g), $11.6 \%$ selenium premix $(600 \mathrm{mg} / \mathrm{kg}$ of Se), $10.5 \%$ trace mineral salt, $9.6 \%$ vitamin A premix (30 IU/g), 6.4\% 4-Plex (Zinpro Corp., Eden Prairie, MN; contains $2.58 \% \mathrm{Zn}, 1.48 \% \mathrm{Mn}, 0.90 \% \mathrm{Cu}, 0.18 \% \mathrm{Co}$, $8.21 \%$ Met, and $3.80 \%$ Lys), $4.3 \%$ vitamin D premix (30 IU $/ g), 4.3 \%$ Rumensin 90 , and $0.48 \%$ ethylenediamine dihydriodide premix $(3.65 \%$ I). Postpartum premix consisted of $47.5 \%$ limestone, $27.9 \%$ of sodium bicarbonate, $10.1 \%$ trace mineral salt, $6.4 \%$ magnesium oxide, $4.5 \%$ vitamin E premix (44 IU/g), 1.79\% 4-Plex (Zinpro Corp., Eden Prairie, MN; contains $2.58 \% \mathrm{Zn}, 1.48 \% \mathrm{Mn}, 0.90 \% \mathrm{Cu}, 0.18 \% \mathrm{Co}, 8.21 \%$ Met, and $3.80 \%$ Lys), $1.1 \%$ selenium premix $(600 \mathrm{mg} / \mathrm{kg}$ of Se), $0.56 \%$ vitamin A premix (30 IU/g), $0.01 \%$ vitamin D premix $(30 \mathrm{IU} / \mathrm{g})$, and $0.03 \%$ ethylenediamine dihydriodide premix $(3.65 \% \mathrm{I})$. 
ues were used to determine ration DM for each month. Water was offered ad libitum, and individual water consumption was measured daily throughout the study. Body condition score was evaluated weekly.

Cows were milked 3 times daily in a milking parlor, and milk yield was recorded at each milking. Milk samples were collected at each milking on 3 consecutive days each week and were analyzed for concentrations of fat, true protein, lactose (B-2000 Infrared Analyzer; Bentley Instruments, Chaska, MN), and urea nitrogen (MUN spectrophotometer, Bentley Instruments) by Heart of America DHIA (Manhattan, KS).

Blood samples were collected from the coccygeal vessels $1 \mathrm{~h}$ before feeding on $\mathrm{d}-21,-7,1,4,7,21$, and 35 relative to calving. Approximately $20 \mathrm{~mL}$ of blood was collected into 4 tubes (Vacutainer, Becton Dickinson, Franklin Lakes, NJ): one 7-mL tube containing potassium EDTA, one 3-mL tube containing potassium EDTA, one 5-mL tube containing heparin, and another 7-mL tube containing potassium oxalate with sodium fluoride as a glycolytic inhibitor. Blood samples from the 7 -mL potassium EDTA tube and the $7-\mathrm{mL}$ tube containing potassium oxalate with sodium fluoride were centrifuged at $2,000 \times g$ for 10 min at $20^{\circ} \mathrm{C}$ immediately after sample collection, and plasma was harvested and frozen at $-20^{\circ} \mathrm{C}$ until subsequent analysis of glucose, BHBA, and NEFA. Plasma samples were analyzed for NEFA using an enzymatic colorimetric procedure (NEFA-HR, Wako Chemicals USA, Richmond, VA), glucose by a colorimetric kit (kit \#439-90901, Wako Chemicals USA), and BHBA using an enzymatic reaction (kit \#H7587-58, Pointe Scientific Inc.). Absorbance was read on a spectrophotometer (Powerwave XS, Biotek Instruments, Winooski, VT), and calculations were conducted using Gen5 software (Biotek Instruments). Blood collected from the 3-mL potassium EDTA tube and the $5-\mathrm{mL}$ tube containing heparin were analyzed for hematology and whole-blood bactericidal capacity, respectively (not reported here).

\section{Data and Statistical Analysis}

Energy-corrected milk yield was calculated as $(0.327$ $\times$ milk yield $)+(12.95 \times$ fat yield $)+(7.65 \times$ protein yield) (Dairy Records Management Systems, 2014). Solids-corrected milk production was calculated as $(12.3 \times \%$ fat $)+(6.56 \times \% \mathrm{SNF})-(0.0752 \times$ milk yield) (Tyrrell and Reid, 1965). To evaluate the efficiency of net energy utilization for milk production, energy supplied by the diet $\left(1.60 \mathrm{Mcal}\right.$ of $\mathrm{NE}_{\mathrm{L}} / \mathrm{kg}$ of $\mathrm{DM}$ at measured intake) and BCS mobilization (410 Mcal $\mathrm{NE}_{\mathrm{L}}$ /unit BCS lost and -500 Mcal of $\mathrm{NE}_{\mathrm{L}}$ /unit BCS gained) were estimated according to NRC (2001). Milk energy output was calculated as $692 \mathrm{kcal} / \mathrm{kg}$ of ECM
(Tyrrell and Reid, 1965). Energy utilization efficiency was then quantified as milk energy output/(diet energy supply + BCS mobilization energy supply).

One cow in the $0 \mathrm{~g} / \mathrm{d}$ treatment group was removed from the study on d 30 postpartum due to difficulty standing up in the tie-stall. Data obtained from this cow before removal were included in all analyses. Feeding behavior variables were calculated from logged data that included the start and end weights as well as start and end times of meals. Meals were combined if the intermeal interval was less than $12 \mathrm{~min}$, a criterion used in our previous study (Mullins et al., 2012) with the same feeding systems and housing facilities. Feed intake, water intake, and feeding behavior data for pre- and postpartum periods were analyzed separately. Data were analyzed using mixed models with repeated measures over time. Models included the fixed effects of treatment, time, and their interaction, and the random effect of cow. Initially, a random effect of block was also included, but this term did not contribute to the fitted models (covariance parameter estimates were 0), and block was therefore removed. Contrast statements were used to assess the overall effect of YC-EHY (control vs. all YC-EHY treatments) as well as the linear and quadratic effects of dose. If treatment by time effects were significant, slices were used to assess effects on specific days. Values were deemed outliers and omitted from analysis when studentized residuals were $>3.0$ or $<-3.0$. After initial outlier removal, the model was repeated, and studentized residuals $>3.5$ or $<-3.5$ were deemed outliers. Significance was declared at $P \leq 0.05$ and tendencies at $0.05<P \leq 0.10$.

\section{RESULTS}

No significant difference was found among groups in prepartum dietary treatment length $(18.1,18.8,17.8$, and $17.2 \pm 1.32 \mathrm{~d}$ for $0,30,60$, and $90 \mathrm{~g} / \mathrm{d}$, respectively; $P=0.86$ ). Actual calving dates ranged from 13 $\mathrm{d}$ before expected calving to $5 \mathrm{~d}$ after expected calving.

\section{Feed Intake, Water Intake, and Feeding Behavior}

Results of feed intake, water intake, and feeding behavior are shown in Table 2 and Figure 1. As expected, across all treatments, DMI decreased $(P<0.01)$ before calving and increased $(P<0.01)$ after parturition. Water intake tended to decrease $(P=0.09)$ before calving and increased dramatically $(P<0.01)$ after parturition. Pre- or postpartum DMI and water intake did not differ $(P>0.10)$ among treatments. Quadratic YC-EHY dose effects $(P<0.05)$ were found for prepartum meal size, meal length, meal frequency, and intermeal interval, reflecting decreased meal size, meal length, and in- 
Table 2. Feed and water intake and feeding behavior responses to yeast culture-enzymatically hydrolyzed yeast (YC-EHY) supplementation during the experimental period ${ }^{1}$

\begin{tabular}{|c|c|c|c|c|c|c|c|c|}
\hline \multirow[b]{2}{*}{ Item } & \multicolumn{4}{|c|}{ Treatment (YC-EHY dose/d) } & \multirow[b]{2}{*}{ SEM } & \multicolumn{3}{|c|}{$P$-value } \\
\hline & $0 \mathrm{~g}$ & $30 \mathrm{~g}$ & $60 \mathrm{~g}$ & $90 \mathrm{~g}$ & & $\begin{array}{l}\text { YC-EHY } \\
\text { vs. control }\end{array}$ & $\begin{array}{c}\text { Linear } \\
\text { dose }\end{array}$ & $\begin{array}{l}\text { Quadratic } \\
\text { dose }\end{array}$ \\
\hline $\mathrm{DMI}, \mathrm{kg} / \mathrm{d}$ & 12.1 & 11.9 & 12.6 & 12.1 & 0.51 & 0.86 & 0.77 & 0.76 \\
\hline Water intake, $\mathrm{L} / \mathrm{d}$ & 49.0 & 48.3 & 49.0 & 51.3 & 2.38 & 0.84 & 0.48 & 0.53 \\
\hline Meal frequency, $\mathrm{d}^{-1}$ & 10.1 & 11.4 & 11.2 & 10.0 & 0.45 & 0.12 & 0.80 & 0.01 \\
\hline Meal length, min & 20.6 & 17.7 & 17.3 & 21.1 & 1.58 & 0.31 & 0.87 & 0.04 \\
\hline \multicolumn{9}{|l|}{ Postpartum measure } \\
\hline DMI, $\mathrm{kg} / \mathrm{d}$ & 21.8 & 19.7 & 21.5 & 22.8 & 1.13 & 0.73 & 0.34 & 0.14 \\
\hline Water intake, $\mathrm{L} / \mathrm{d}$ & 105.6 & 96.1 & 105.6 & 105.2 & 5.15 & 0.59 & 0.72 & 0.40 \\
\hline Meal frequency, $\mathrm{d}^{-1}$ & 12.8 & 13.1 & 13.5 & 12.2 & 0.62 & 0.85 & 0.62 & 0.19 \\
\hline Intermeal interval, h & 1.50 & 1.50 & 1.42 & 1.60 & 0.08 & 0.90 & 0.53 & 0.29 \\
\hline Meal size, kg of DM & 1.81 & 1.69 & 1.76 & 1.93 & 0.10 & 0.87 & 0.34 & 0.14 \\
\hline
\end{tabular}

${ }^{1}$ Values are least squares means \pm SEM, $\mathrm{n}=9$ to 10.

termeal interval and increased meal frequency for cows receiving 30 and $60 \mathrm{~g} / \mathrm{d}$ doses. When prepartum data points were adjusted to reflect day relative to actual parturition, treatment means were similar and statistical analysis resulted in identical conclusions (data not shown). Postpartum feeding behavior was not affected $(P>0.10)$ by treatments.

\section{Milk Production and Body Condition}

As shown in Table 3 and Figure 2A, milk yield was not affected $(P>0.10)$ by treatments. Milk fat percentage tended to increase $(P=0.09$, quadratic dose effect) in cows receiving 30 and $60 \mathrm{~g} / \mathrm{d}$ YC-EHY doses. Tendencies for increased percentages of milk protein $(P$ $=0.08$, linear dose effect $)$ and lactose $(P=0.10$, linear dose effect) were detected with increasing dose. Milk composition yields, SCM, and ECM (Figure 2B) were not affected $(P>0.10)$ by treatments. Body condition score (Figure $2 \mathrm{C}$ ) decreased dramatically $(P<0.01)$ after calving but was unaffected $(P=0.90)$ by treatments. Energy utilization efficiency was estimated by accounting for energy supply via DMI as well as BCS mobilization, and this measure tended to be increased by YC-EHY supplementation $(P=0.08)$, with no dose effect detected.

\section{Plasma Metabolites}

As shown in Figure 3, significant day effects $(P<$ 0.01 ) were observed for plasma glucose, BHBA, and NEFA, reflecting dramatic metabolic and endocrine changes during the transition period. A tendency for a quadratic YC-EHY dose effect $(P=0.06)$ was detected for glucose, indicating that 30 and $60 \mathrm{~g} / \mathrm{d}$ doses tended to decrease plasma glucose $(69.6,66.1,67.0$, and 68.7 $\pm 1.33 \mathrm{mg} / \mathrm{dL}$ for $0,30,60$, and $90 \mathrm{~g} / \mathrm{d}$, respectively, throughout the experimental period), but no YC-EHY vs. control $(P=0.14)$, linear dose $(P=0.75)$, or treatment $\times$ day $(P=0.99)$ effects were detected. Interestingly, compared with the control, YC-EHY increased plasma BHBA $(P<0.01 ; 661.0,882.0,759.8$, and $736.4 \pm 41.3 \mu M$ for $0,30,60$, and $90 \mathrm{~g} / \mathrm{d}$, respectively, throughout the experimental period). A significant quadratic dose effect $(P<0.01)$ was also detected. Although plasma NEFA was numerically increased by 30 and $60 \mathrm{~g} / \mathrm{d}$ doses $(P=0.12$, quadratic dose effect; $496.8,565.7,566.3$, and $480.9 \pm 48.7 \mu M$ for $0,30,60$, and $90 \mathrm{~g} / \mathrm{d}$, respectively, throughout the experimental period), no YC-EHY vs. control $(P=0.47)$ or treatment $\times$ day $(P=0.73)$ effects were detected.

\section{DISCUSSION}

The transition period imposes tremendous stress on dairy cows and may result in inadequate nutrient and energy intake to support the onset of lactation. In this study, we attempted to evaluate if YC-EHY supplementation would modulate DMI, feeding behavior, and milk production of transition cows. We found that DM and water intake decreased before parturition and increased dramatically after calving, but they were not affected by treatments either pre- or postpartum. Dann et al. (2000) reported that yeast culture increased DMI both pre- and postpartum in Jersey cows. Ramsing et al. (2009) recently reported that cows supplemented with yeast culture at $57 \mathrm{~g} / \mathrm{d}$ throughout the transition period had an increased prepartum DMI (by 1.5 
A

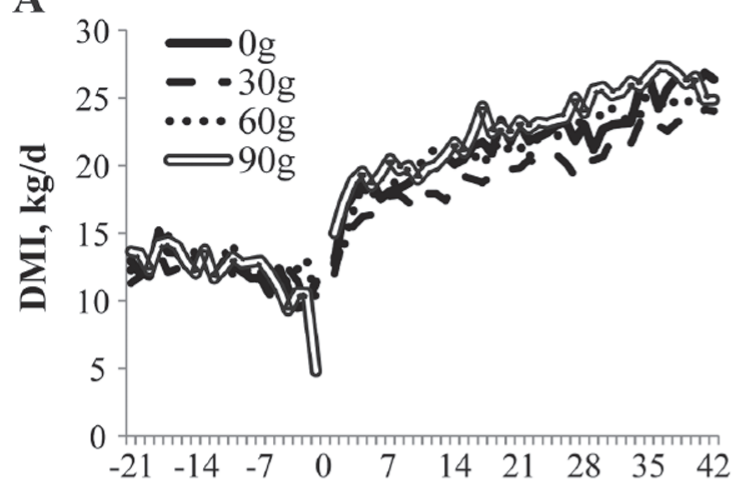

C

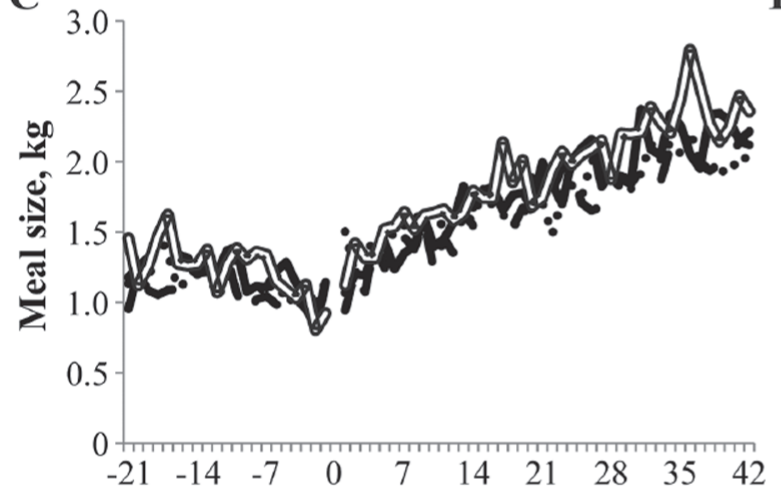

B

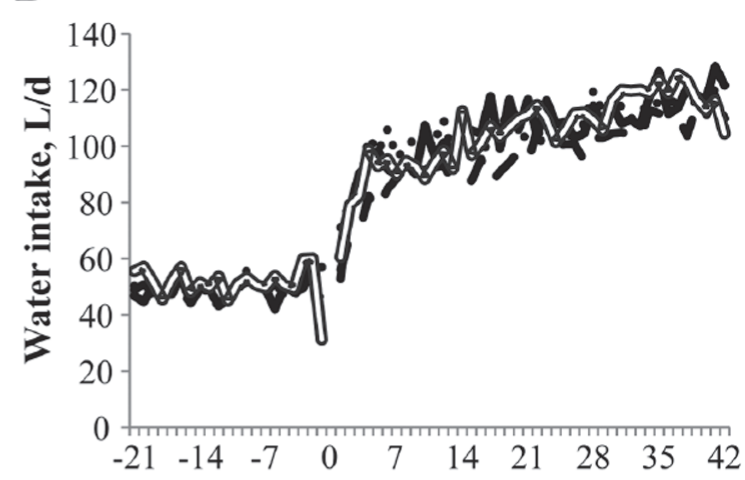

D

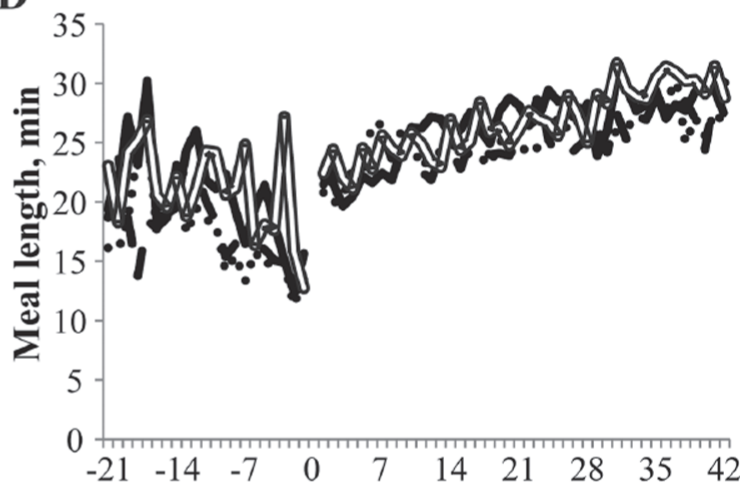

E

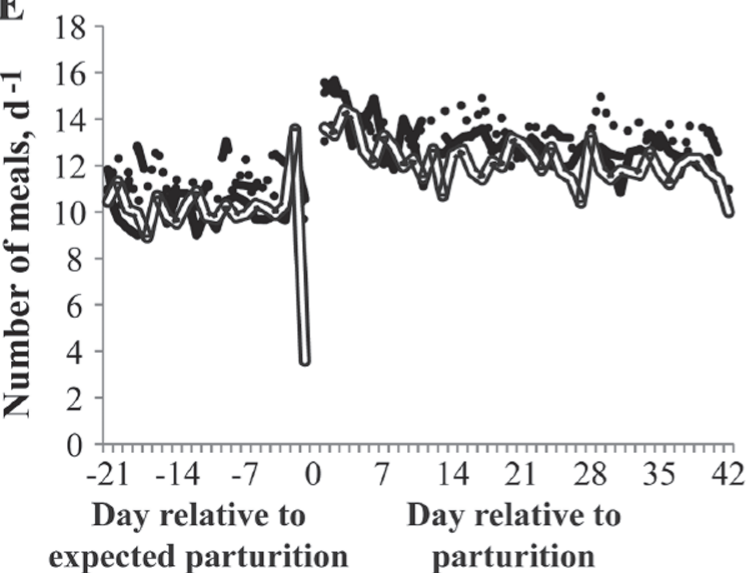

F

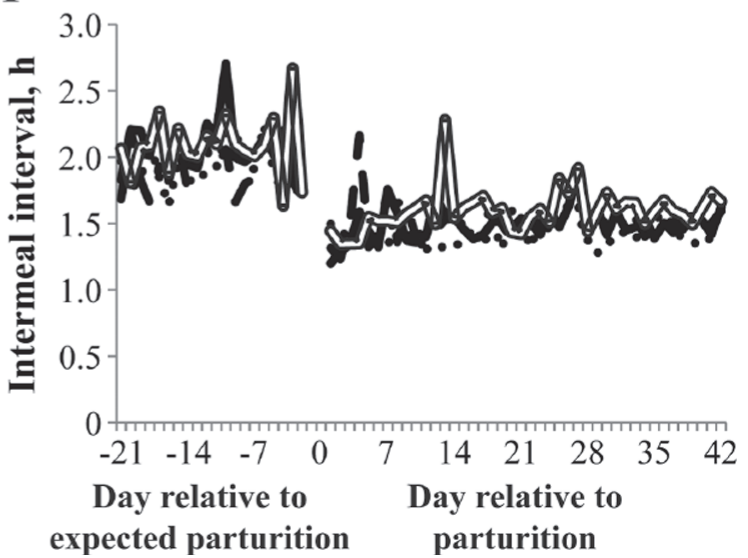

Figure 1. Dry matter intake (A), water intake (B), meal size (C), meal length (D), number of meals (E), and intermeal interval (F) during the experimental period. Yeast culture-enzymatically hydrolyzed yeast (YC-EHY) was supplemented at 0, 30, 60, or 90 g/d to transition dairy cows from $21 \mathrm{~d}$ before expected calving to $42 \mathrm{~d}$ after calving. No treatment $\times$ day $(P>0.10)$ effects were observed, and no treatment effects were observed except where noted. $(\mathrm{A})$ : Day effects $(P<0.01)$ both pre- and postpartum were observed; prepartum SEM $=0.86$, postpartum $\mathrm{SEM}=1.44$. $(\mathrm{B}):$ A tendency for day effect prepartum $(P=0.09)$ and a day effect postpartum $(P<0.01)$ were observed; prepartum SEM $=$ 4.63, postpartum SEM $=7.02$. $(\mathrm{C})$ : During the prepartum period, a quadratic effect of YC-EHY was observed $(P=0.04)$. Day effects $(P<0.01)$ both pre- and postpartum were observed; prepartum SEM $=0.11$, postpartum SEM $=0.38$. (D): During the prepartum period, a quadratic effect of YC-EHY was observed $(P=0.04)$. Day effects $(P<0.01)$ both pre- and postpartum were observed; prepartum SEM $=2.65$, postpartum $\mathrm{SEM}=1.81$. $(\mathrm{E})$ : During the prepartum period, a quadratic effect of YC-EHY was observed $(P<0.01)$. A tendency for day effect prepartum $(P=0.07)$ and a day effect postpartum $(P=0.03)$ were observed; prepartum SEM $=0.93$, postpartum SEM $=1.00$. $(\mathrm{F})$ : During the prepartum period, a quadratic effect of YC-EHY was observed $(P=0.02)$. A day effect was observed prepartum $(P<0.01)$, but not postpartum $(P$ $=0.18)$; prepartum SEM $=0.17$, postpartum SEM $=0.14$. Values are least squares means \pm standard error of the means, $\mathrm{n}=9$ to 10 for all. 
Table 3. Milk production and composition responses to yeast culture-enzymatically hydrolyzed yeast (YC-EHY) supplementation during the experimental period ${ }^{1}$

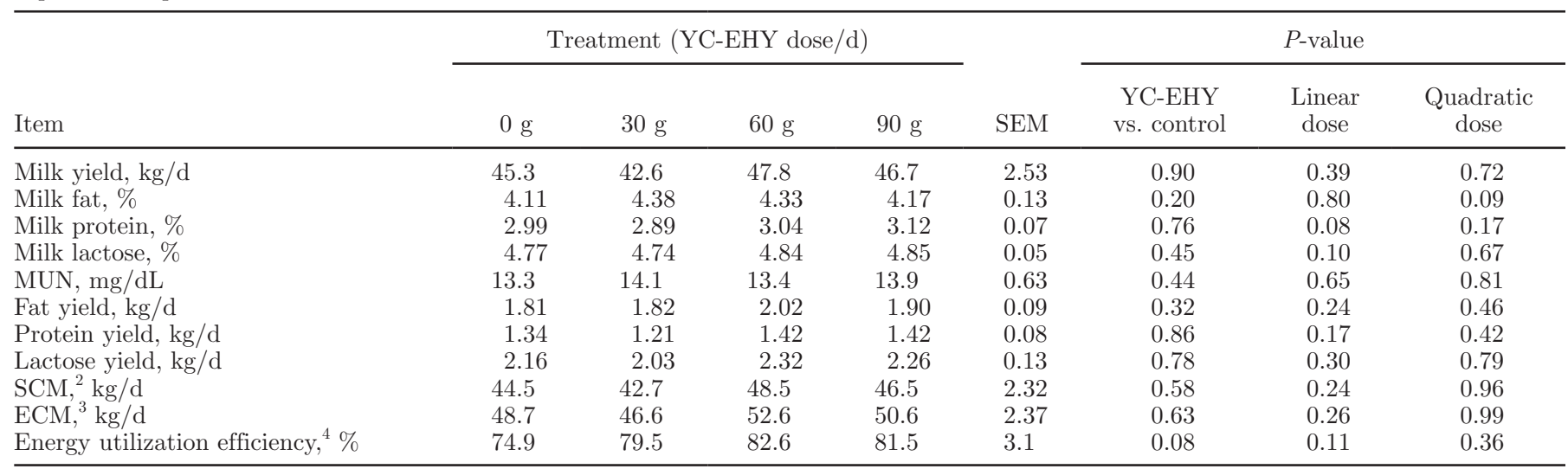

${ }^{1}$ Values are least squares means \pm standard error of the means, $\mathrm{n}=9$ to 10 .

${ }^{2} \mathrm{SCM}=(12.3 \times \%$ fat $)+(6.56 \times \% \mathrm{SNF})-(0.0752 \times$ milk yield $) ;($ Tyrrell and Reid, 1965$)$.

${ }^{3} \mathrm{ECM}=(0.327 \times$ milk yield $)+(12.95 \times$ fat yield $)+(7.65 \times$ protein yield $) ;($ Dairy Records Management Systems, 2014 $)$.

${ }^{4}$ Milk energy output divided by energy provided by feed and BCS mobilization by week (NRC, 2001).

$\mathrm{kg} / \mathrm{d})$, though postpartum DMI was not affected by treatments. Other studies (Arambel and Kent, 1990; Swartz et al., 1994; Robinson, 1997), however, reported no effects of yeast products on DMI.

Changes in DMI ultimately result from changes in feeding behavior, quantified as number of meals consumed daily, the length of each meal, and the rate of eating that occurs during meals (Grant and Albright, 1995). Similar to the changes in DMI, we observed that most of the feeding behavior variables changed over time either pre- or postpartum. Consistent with the finding (Ramsing et al., 2009) that yeast culture increased the number of meals per day in prepartum cows, we observed increased meal frequency for cows that received 30 and $60 \mathrm{~g} / \mathrm{d}$ YC-EHY treatments. Ramsing et al. (2009) reported no difference in prepartum meal size, but here we detected a quadratic decrease in response to YC-EHY. The reasons for the discrepancies between the 2 studies are not clear, but differences in feeding systems, meal criteria and calculation methods, and treatment products may have contributed. In our study, the increase in meals consumed per day and decreased meal size may have resulted in more consistent prepartum intake patterns throughout the day. Although not measured directly, this modulated feeding behavior may be associated with improved rumen fermentation characteristics in response to yeast product supplementation (Piva et al., 1993; Yoon and Stern, 1996; Marden et al., 2008). No significant treatment effects were observed for postpartum feeding behavior, though numerical patterns in meal frequency and size were similar to those observed prepartum. If these changes attenuate fluctuations of rumen $\mathrm{pH}$, then yeast product could benefit early-lactation cows by allowing them to better adapt to the sudden dietary shift. It should be noted that cows were in a loose housing facility prepartum and in tie-stalls postpartum, so the changes in feeding patterns from pre- to postpartum likely reflect differences in feeding behavior of cows in pen vs. tiestall housing (Grant and Albright, 1995) in addition to a true stage of production effect. Regulation of feeding behavior and feed intake is complex and is controlled by gut fill and chemostatic mechanisms. Factors such as feeding management, environment, health, and social interactions could affect feeding behavior and feed intake as well (Grant and Albright, 1995).

Milk and milk component yields were not affected by YC-EHY supplementation, although tendencies were observed for a quadratic increase in milk fat percentage and linear increases in milk protein and lactose percentages with increasing dose. Many studies (Arambel and Kent, 1990; Swartz et al., 1994; Robinson, 1997) have reported no significant effects of yeast products on milk yield, and a few experiments have reported positive milk responses (Ramsing et al., 2009; Nocek et al., 2011). A recent study (Zaworski et al., 2014) found yeast product supplementation at 56 or $112 \mathrm{~g} / \mathrm{d}$ during the transition period increased milk yield by $5.2 \pm$ $2.3 \mathrm{~kg} / \mathrm{d}$ during the first $4 \mathrm{wk}$ postpartum. These data suggest that milk production responses to yeast product supplementation are rather variable; differences in parities, stages of lactation, product derivation, and environmental conditions could all contribute to the discrepancies. Given the large variability in milk yield in early lactation, more animals are needed to achieve adequate power to detect differences in productivity.

One of the key reported benefits of feeding yeast products is increased feed efficiency (Schingoethe et al., 

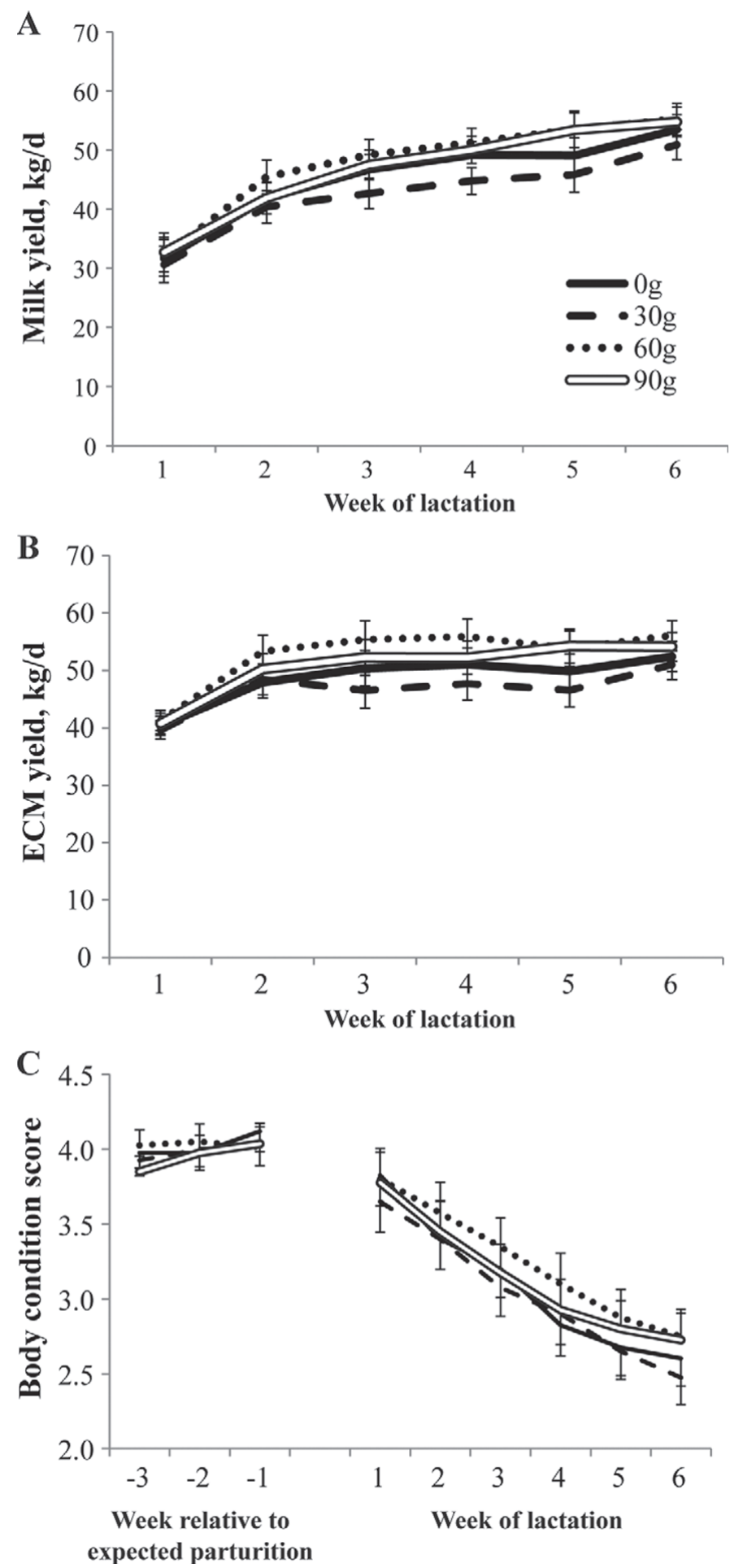

Figure 2. Milk yield (A), ECM yield (B), and BCS (C) during the experimental period. Yeast culture-enzymatically hydrolyzed yeast was supplemented at $0,30,60$, or $90 \mathrm{~g} / \mathrm{d}$ to transition dairy cows from $21 \mathrm{~d}$ before expected calving to $42 \mathrm{~d}$ after calving. No treatment $(P>$ $0.10)$ or treatment $\times$ day $(P>0.10)$ effects were observed for these variables. (A) A week effect $(P<0.01)$ was observed. (B) A week effect $(P<0.01)$ was observed. $(\mathrm{C})$ A day effect $(P<0.01)$ was observed. Values are least squares means \pm standard error of the means, $\mathrm{n}=9$ to 10 for all.
2004; Cooke et al., 2007). However, simple calculation of ECM yield divided by DMI in early lactation cows can be misleading, because a relatively large proportion of energy supply comes from mobilization of stored nutrients during this period. We therefore estimated energy utilization efficiency in this study as milk energy output divided by the sum of energy from feed and BCS mobilization. Based on this analysis YC-EHY tended to improve energy efficiency, independent of dose. The response could theoretically be a result of (1) enhanced energy digestibility; (2) decreased maintenance energy requirements; or (3) improved efficiency of net energy use for milk synthesis. Little evidence is available that yeast products influence postabsorptive metabolic efficiency, although it is possible that modulation of the immune system by yeast could influence maintenance energy requirements (Zaworski et al., 2014). Substantial evidence is available, however, that yeast supplementation can increase OM digestibility in ruminants, thereby increasing energy harvest from the diet (Desnoyers et al., 2009). Although not a direct measure, the tendency for increased energy efficiency with YC-EHY in our study is consistent with an increase in diet digestibility.

The dramatic changes in plasma metabolites throughout the transition period observed in this study are similar to the patterns observed in many previous studies (Morey et al., 2011; Mullins et al., 2012). Supplementation of 30 and $60 \mathrm{~g} / \mathrm{d}$ YC-EHY tended to decrease plasma glucose. Yeast product supplementation increased plasma BHBA, and a significant quadratic dose effect was also detected, with the 30 $\mathrm{g} / \mathrm{d}$ dose having the greatest effect on BHBA. One source of circulating BHBA is the rumen epithelium, where ruminally produced butyrate can be converted to BHBA. However, little evidence is available from either in vivo (Harrison et al., 1988) or in vitro (Sullivan and Martin, 1999) studies that yeast products increase butyrate production. In this study, YC-EHY altered meal frequency, but past work has not shown evidence of increased butyrate production with increased meal frequency (Sutton et al., 1988).

Hepatic ketogenesis is a key source of circulating BHBA in early lactation cows. In addition to significant effects on plasma BHBA, the 30 and $60 \mathrm{~g} / \mathrm{d}$ YC-EHY treatments also numerically increased plasma NEFA. These changes point to an enhanced lipid mobilization and hepatic ketogenesis in response to the intermediate YC-EHY doses, which is consistent with the finding that 30 and $60 \mathrm{~g} / \mathrm{d}$ doses tended to increase milk fat percentage. The reasons underlying this observation are not clear, but it is unlikely that yeast product had a direct effect on lipid metabolism. Cows receiving 30 $\mathrm{g} / \mathrm{d}$ had a numerical decrease in postpartum DMI of $2.1 \mathrm{~kg} / \mathrm{d}$, and decreased feed intake in the transition 

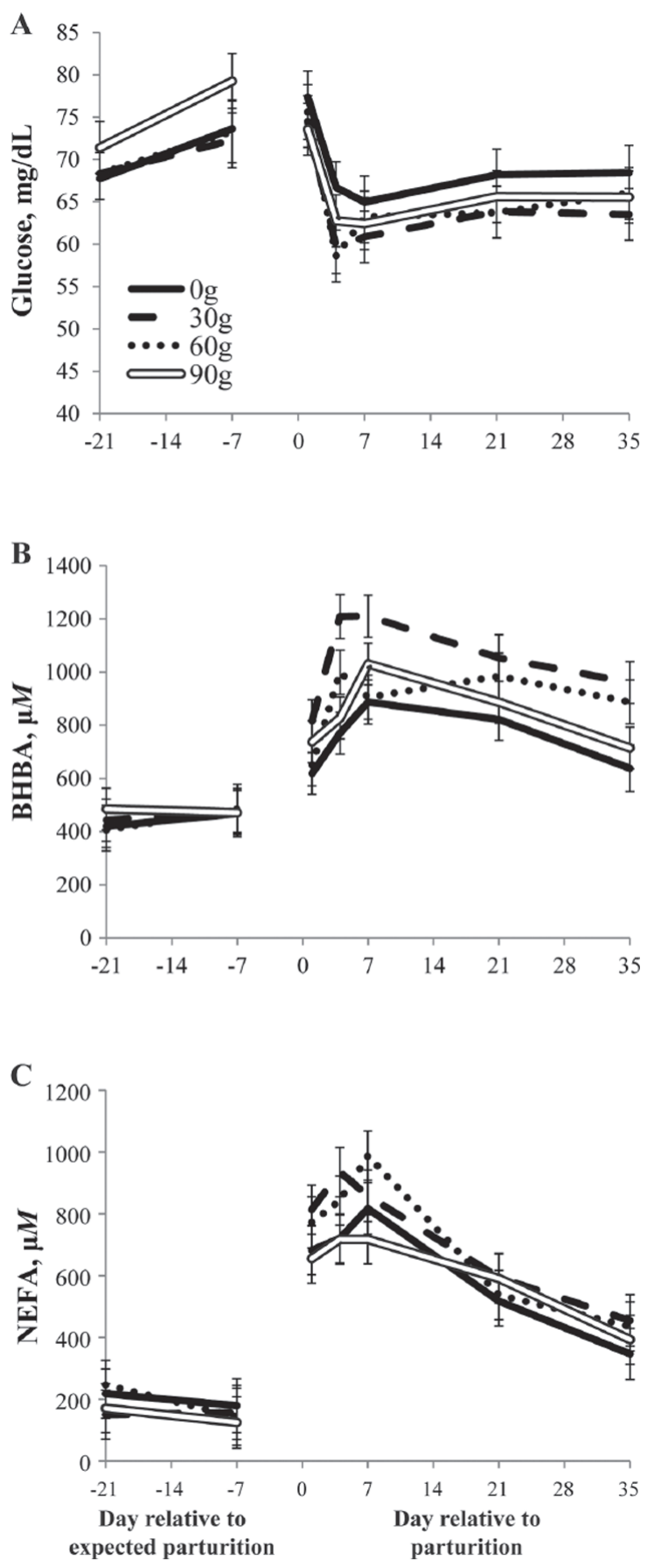

Figure 3. Concentrations of plasma metabolites during the experimental period. Yeast culture-enzymatically hydrolyzed yeast was supplemented at $0,30,60$, or $90 \mathrm{~g} / \mathrm{d}$ to transition dairy cows from 21 $\mathrm{d}$ before expected calving to $42 \mathrm{~d}$ after calving. (A) Glucose: a day effect $(P<0.01)$ and a tendency for a quadratic dose effect $(P=0.06)$ were found, but no yeast product versus control $(P=0.14)$, linear dose $(P=0.75)$, or treatment $\times$ day $(P=0.99)$ effects. (B) BHBA: day $(P<0.01)$, yeast product vs. control $(P<0.01)$, and quadratic dose $(P<0.01)$ effects were present, but no linear dose $(P=0.57)$ or treatment $\times$ day $(P=0.20)$ effects. $(\mathrm{C})$ NEFA: a day effect $(P<0.01)$ was present, but no yeast product vs. control $(P=0.47)$, linear dose $(P=0.83)$, quadratic dose $(P=0.12)$, or treatment $\times$ day $(P=0.73)$ effects. Values are least squares means \pm standard error of the means, $\mathrm{n}=9$ to 10 for all. period is a key risk factor for elevated plasma NEFA and BHBA concentrations (Grummer, 1995).

Together, these data suggest that YC-EHY product supplementation did not affect milk production or DMI, but modulated feeding behavior and metabolism in transition dairy cows. A key finding was several quadratic responses to increasing YC-EHY dose. Relatively few studies in transition dairy cows have been designed to evaluate the dose-response to yeast products, limiting our ability to assess whether quadratic responses are common. Zaworski et al. (2014) recently reported that a yeast product fed at $56 \mathrm{~g} / \mathrm{d}$ through the transition period increased milk production, with no additional benefit observed for the $112 \mathrm{~g} / \mathrm{d}$ dose. In the current study, a similar dose of YC-EHY $(60 \mathrm{~g} / \mathrm{d})$ resulted in favorable changes in feeding behavior and supported the numerically greatest energy efficiency and milk yield postpartum. Although a more powerful study would be required to clearly identify the ideal dose for production outcomes, this intermediate dose appears to be the most promising for future work.

\section{ACKNOWLEDGMENTS}

Contribution no. 14-353-J from the Kansas Agricultural Experiment Station. We thank Vi-COR Inc. (Mason City, IA) for providing funding to support this study. We thank Michael Scheffel, Nicole Eberhart, Sam Kennett-Vachon, Blake Madsen, Erin Atsaves, Jacob Dreiling, and Fabian Vargas at Kansas State University for animal care and technical assistance.

\section{REFERENCES}

Arambel, M. J., and B. A. Kent. 1990. Effect of yeast culture on nutrient digestibility and milk yield response in early- to midlactation dairy cows. J. Dairy Sci. 73:1560-1563.

Callaway, E. S., and S. A. Martin. 1997. Effects of a Saccharomyces cerevisiae culture on ruminal bacteria that utilize lactate and digest cellulose. J. Dairy Sci. 80:2035-2044.

Cooke, K. M., J. K. Bernard, and J. W. West. 2007. Performance of lactating dairy cows fed whole cottonseed coated with gelatinized starch plus urea or yeast culture. J. Dairy Sci. 90:360-364.

Dairy Records Management Systems. 2014. DHI glossary. Accessed May 11, 2014. http://www.drms.org/PDF/materials/glossary.pdf.

Dann, H. M., J. K. Drackley, G. C. McCoy, M. F. Hutjens, and J. E. Garrett. 2000. Effects of yeast culture (Saccaromyces cerevisiae) on prepartum intake and postpartum intake and milk production of Jersey cows. J. Dairy Sci. 83:123-127.

Desnoyers, M., S. Giger-Reverdin, G. Bertin, C. Duvaux-Ponter, and D. Sauvant. 2009. Meta-analysis of the influence of Saccharomyces cerevisiae supplementation on ruminal parameters and milk production of ruminants. J. Dairy Sci. 92:1620-1632.

Grant, R. J., and J. L. Albright. 1995. Feeding behavior and management factors during the transition period in dairy cattle. J. Anim. Sci. 73:2791-2803.

Grummer, R. R. 1995. Impact of changes in organic nutrient metabolism on feeding the transition dairy cow. J. Anim. Sci. 73:28202833.

Harrison, G. A., R. W. Hemken, K. A. Dawson, R. J. Harmon, and K. B. Barker. 1988. Influence of addition of yeast culture supplement 
to diets of lactating cows on ruminal fermentation and microbial populations. J. Dairy Sci. 71:2967-2975.

Marden, J. P., C. Julien, V. Monteils, E. Auclair, R. Moncoulon, and C. Bayourthe. 2008. How does live yeast differ from sodium bicarbonate to stabilize ruminal $\mathrm{pH}$ in high-yielding dairy cows? J. Dairy Sci. 91:3528-3535.

Morey, S. D., L. K. Mamedova, D. E. Anderson, C. K. Armendariz, E. C. Titgemeyer, and B. J. Bradford. 2011. Effects of encapsulated niacin on metabolism and production of periparturient dairy cows. J. Dairy Sci. 94:5090-5104.

Mullins, C. R., L. K. Mamedova, M. J. Brouk, C. E. Moore, H. B Green, K. L. Perfield, J. F. Smith, J. P. Harner, and B. J. Bradford. 2012. Effects of monensin on metabolic parameters, feeding behavior, and productivity of transition dairy cows. J. Dairy Sci. 95:1323-1336.

Newbold, C. J., R. J. Wallace, and F. M. McIntosh. 1996. Mode of action of the yeast Saccharomyces cerevisiae as a feed additive for ruminants. Br. J. Nutr. 76:249-261.

Nocek, J. E., M. G. Holt, and J. Oppy. 2011. Effects of supplementation with yeast culture and enzymatically hydrolyzed yeast on performance of early lactation dairy cattle. J. Dairy Sci. 94:40464056.

NRC. 2001. Nutrient Requirements of Dairy Cattle. 7th rev. ed. Natl. Acad. Sci., Washington, DC.

Piva, G., S. Belladonna, G. Fusconi, and F. Sicbaldi. 1993. Effects of yeast on dairy cow performance, ruminal fermentation, blood components, and milk manufacturing properties. J. Dairy Sci. $76: 2717-2722$

Poppy, G. D., A. R. Rabiee, I. J. Lean, W. K. Sanchez, K. L. Dorton, and P. S. Morley. 2012. A meta-analysis of the effects of feeding yeast culture produced by anaerobic fermentation of Saccharomy- ces cerevisiae on milk production of lactating dairy cows. J. Dairy Sci. 95:6027-6041.

Ramsing, E. M., J. A. Davidson, P. D. French, I. Yoon, M. Keller, and H. Peters-Fleckenstein. 2009. Effect of yeast culture on peripartum intake and milk production of primiparous and multiparous Holstein cows. Prof. Anim. Sci. 25:487-495.

Robinson, P. H. 1997. Effect of yeast culture (Saccharomyces cerevisiae) on adaptation of cows to diets postpartum. J. Dairy Sci 80:1119-1125

Schingoethe, D. J., K. N. Linke, K. F. Kalscheur, A. R. Hippen, D. R. Rennich, and I. Yoon. 2004. Feed efficiency of mid-lactation dairy cows fed yeast culture during summer. J. Dairy Sci. 87:4178-4181.

Sullivan, H. M., and S. A. Martin. 1999. Effects of a Saccharomyces cerevisiae culture on in vitro mixed ruminal microorganism fermentation. J. Dairy Sci. 82:2011-2016.

Sutton, J. D., I. C. Hart, S. V. Morant, E. Schuller, and A. D. Simmonds. 1988. Feeding frequency for lactating cows: Diurnal patterns of hormones and metabolites in peripheral blood in relation to milk-fat concentration. Br. J. Nutr. 60:265-274.

Swartz, D. L., L. D. Muller, G. W. Rogers, and G. A. Varga. 1994 Effect of yeast cultures on performance of lactating dairy cows: A field study. J. Dairy Sci. 77:3073-3080.

Tyrrell, H. F., and J. T. Reid. 1965. Prediction of the energy value of cow's milk. J. Dairy Sci. 48:1215-1223.

Yoon, I. K., and M. D. Stern. 1996. Effects of Saccharomyces cerevisiae and Aspergillus oryzae cultures on ruminal fermentation in dairy cows. J. Dairy Sci. 79:411-417.

Zaworski, E. M., C. M. Shriver-Munsch, N. A. Fadden, W. K. Sanchez, I. Yoon, and G. Bobe. 2014. Effects of feeding various dosages of Saccharomyces cerevisiae fermentation product in transition dairy cows. J. Dairy Sci. 97:3081-3098. 